University of Wollongong

Research Online

Faculty of Social Sciences - Papers (Archive) Faculty of Arts, Social Sciences \& Humanities

$1-1-2017$

\title{
A brief historical perspective on the advent of brain oscillations in the biological and psychological disciplines
}

Sirel Karakas

Dogus University

Robert J. Barry

University of Wollongong, rbarry@uow.edu.au

Follow this and additional works at: https://ro.uow.edu.au/sspapers

Part of the Education Commons, and the Social and Behavioral Sciences Commons

Research Online is the open access institutional repository for the University of Wollongong. For further information contact the UOW Library: research-pubs@uow.edu.au 


\title{
A brief historical perspective on the advent of brain oscillations in the biological and psychological disciplines
}

\author{
Abstract \\ We aim to review the historical evolution that has led to the study of the brain (body)-mind relationship \\ based on brain oscillations, to outline and illustrate the principles of neuro-oscillatory dynamics using \\ research findings. The paper addresses the relevant developments in behavioral sciences after Wundt \\ established the science of psychology, and developments in the neurosciences after alpha and gamma \\ oscillations were discovered by Berger and Adrian, respectively. Basic neuroscientific studies have led to \\ a number of principles: (1) spontaneous EEG is composed of a set of oscillatory components, (2) the \\ brain responds with oscillatory activity, (3) poststimulus oscillatory activity is a function of prestimulus \\ activity, (4) the brain response results from a superposition of oscillatory components, (5) there are \\ multiplicities with regard to oscillations and functions, and (6) oscillations are spatially integrated. \\ Findings of clinical studies suggest that oscillatory responses can serve as biomarkers for \\ neuropsychiatric disorders. However, the field of psychology is still making limited use of neuro- \\ oscillatory dynamics for a bio-behavioral understanding of cognitive-affective processes.
}

\section{Keywords}

oscillations, brain, advent, perspective, disciplines, psychological, historical, biological, brief

\section{Disciplines}

Education | Social and Behavioral Sciences

\section{Publication Details}

Karakas, S. \& Barry, R. J. (2017). A brief historical perspective on the advent of brain oscillations in the biological and psychological disciplines. Neuroscience and Biobehavioral Reviews, 75 335-347. 


\title{
A BRIEF HISTORICAL PERSPECTIVE ON THE ADVENT OF BRAIN OSCILLATIONS IN THE BIOLOGICAL
} AND PSYCHOLOGICAL DISCIPLINES

\author{
Sirel Karakaş and Robert J. Barry ${ }^{\mathrm{b}}$ \\ aDogus University, Department of Psychology, 34722 Kadıköy, İstanbul, Turkey \\ skarakas@dogus.edu.tr

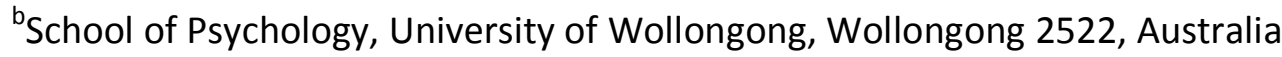 \\ rbarry@uow.edu.au
}

\section{Corresponding author:}

Prof. Dr. Sirel Karakaş

Tepe Prime / Neurometrika Medical Technologies, LLC

Mustafa Kemal Mah., Dumlupınar Bulv., No 266, C-90

06800 Çankaya, Ankara

Turkey

Phone: +90 312- 2992148

E-mail: sirel.karakas@gmail.com 


\section{ABSTRACT}

We aim to review the historical evolution that has led to the study of the brain (body)-mind relationship based on brain oscillations, to outline and illustrate the principles of neurooscillatory dynamics using research findings. The paper addresses the relevant developments in behavioral sciences after Wundt established the science of psychology, and developments in the neurosciences after alpha and gamma oscillations were discovered by Berger and Adrian, respectively. Basic neuroscientific studies have led to a number of principles: (1) spontaneous EEG is composed of a set of oscillatory components, (2) the brain responds with oscillatory activity, (3) poststimulus oscillatory activity is a function of prestimulus activity, (4) the brain response results from a superposition of oscillatory components, (5) there are multiplicities with regard to oscillations and functions, and (6) oscillations are spatially integrated. Findings of clinical studies suggest that oscillatory responses can serve as biomarkers for neuropsychiatric disorders. However, the field of psychology is still making limited use of neuro-oscillatory dynamics for a bio-behavioral understanding of cognitive-affective processes.

Keywords: Oscillatory dynamics; principles of oscillatory dynamics; delta; theta; alpha; beta; gamma; spatiotemporal integration; coherence; biomarker. 


\section{Introduction}

The present paper provides a brief and selective perspective on the historical evolution that has led to the study of the brain (body)-mind relationship based on brain oscillations. The paper is an overview of the current principles of oscillatory dynamics. As such, it illustrates these principles using research findings, demonstrates the applicability of the principles to neuropsychiatric disorders, and discusses the attitude of academic psychologists to the brainmind relationship and the study of the relationship via brain oscillations. Being a journal article, this paper accounts for only the most significant events and scientists in the three centuries over which the evolution towards the oscillatory perspective occurred. However, we point to review articles for the reader who is interested in further information on the subject matter.

The history of oscillatory brain dynamics may be traced back to two historical events, the first of which is prescientific, and the other scientific but precognitive. Mesmer is the key personage for the prescientific event: Any discussion on brain electricity should acknowledge the work of Mesmer (Pearson, 1790), as he was the first person to discuss what he called "animal magnetism". Although ridiculed and even discredited in his time, this approach ingeniously underlined the fact that living creatures have an electric field by which they can influence others. In his classic work, Zweig (1932) describes Mesmer as one of the three "mental healers" (the other two were Freud and Eddy) who emphasized the relationship between the body and the mental-emotional life in health and in illness. The second, scientific but precognitive, event was the discovery of the motor strip by Fritsch and Hitzig. Until the late part of the 19th century, dogma had dictated that the brain is inexcitable. Fritsch and Hitzig (1870) abolished this dogma and demonstrated that brain tissue is responsive to electrical stimulation.

\subsection{Early developments in psychology}

At nearly the same time as the advent of brain electricity as a mechanism of brain function, Wundt was emancipating psychology, the discipline that studied the "mind" component of the brain-mind dichotomy, from philosophy. Wundt founded the new science in 1879, the year he 
established an experimental psychology laboratory in Leipzig. The founder christened the new science as "physiological psychology", suggesting that this new science would study not only the mind but also deal with physiology (Wundt, 1874). However, Wundt was using the term "physiology" to refer not to the body/brain correlate of the mind but to the methodology, namely experimental, that psychology would be using (Boring, 1950).

This founding was followed by the classical schools of psychology, the critical aspects of which are summarized in Table 1 (for a review, see Schultz, 2000). The founder of the earliest school, structuralism, was again Wundt. For this school, psychology should analyze consciousness of normal humans into its constituent elements, to discover how these elements are mentally connected, and to determine the laws of their connections. This statement includes two very critical issues. Firstly, Wundt was not referring to the organismic correlates of mental functioning when he was using the term "physiology". Secondly, in the term "mental connections", we are confronted with the psychological forerunner of the much later concept of "cognits" by Fuster (1995; for a review, see Karakaş \& Başar, 2006a, b) and the concept of "connectivity" (Başar et al., 2014, 2015; Başar and Düzgün, 2015, Başar, Güntekin, Yener and Başar-Eroğlu, 2016; Engell \& McCarthy, 2010; Martini, et al., 2012; Özerdem et al., 2011; Rubinov and Sporns, 2010).

Insert Table 1 about here.

Structuralism sought to answer the "what?" of consciousness and thus sought to discover the contents of the mind. The second school of psychology, functionalism, sought to answer the "why" or "how" of the mind. Under the influence of functionalism, which was founded in 1896, psychologists began studying the mental activity of organisms (humans and infra-human species) in their struggle to adapt to environmental challenges. W. James, who was considered to be the founder of the functionalist school, published his groundbreaking book, Principles of 
Psychology, in 1890. In his book, the stream of consciousness and attention, among other subjects, were ingeniously discussed and laid out nearly as we know them today. Another stage of psychology was marked by the Gestalt school. Wertheimer founded the school in 1913. Inspired by Heidel (1977), the slogan of this school was formulated as "The whole is other than the sum of its parts." (cited in Dewey, 2007, p. 383; Koffka, 1935). The Gestalt school was basically a reaction to the atomistic, analytic, and static approach of structuralism. The Gestalt approach assumed that the mind generates whole forms and global figures, and that human experience is an organized whole (for a treatise on the schools, see Boring, 1950; Schultz, 2000).This statement is the psychological forerunner of the current theoretical concept of the whole brain work (for a review, see Karakaş and Başar, 2006b) and the empirical data on the intricate selective connectivity pattern that support it (for a review, see Başar, Güntekin, Yener \& Başar-Eroğlu, 2016).

Each classical school of psychology thus emphasized a different concept, but none of them was related to the body/brain component of the mind, or to the relationship between the two components. It was Hebb (1949) who theoretically explained the holistic functioning of the mind on the basis of electrical processes of the brain. His concept of reverberating networks (or the Hebbian networks) is the theoretical ancestor of the brain oscillations, and of the empiricial concept of connectivity. In modern times, the connectivity patterns are illustrated in the CLAIR Atlas (Başar \& Düzgün, 2015) as coherence functions between the oscillatory components of selected brain areas.

According to the foregoing developments; when brain electricity was only a possibility, scientific psychology had already been founded as an "experimental psychology", and between 1879 and 1930, it had passed through an era involving several schools of psychology. Throughout these schools, the importance of the structure (structuralism), function (functionalism), and holistic processing in the mind (Gestalt) was emphasized. Behaviorism then arrived, and the study of the mind was discontinued. Under the insistence of the behavioristic school to use only the observables (namely, the stimulus and response), the field turned into a 
stimulus-response psychology. Everything in between - collectively speaking, "the mind" - was deemed insignificant for understanding behavior. Thus, although it was originally founded as a physiological psychology, psychological thought vacillated between behavior on the one hand and the constructs of consciousness and mind/cognition on the other. With the "radical" behavioristic school, psychology lost even this longstanding construct, the mind. Only with the cognitive revolution, around the 1950s, could cognition and mind find their way back into the realm of psychology once again.

In those days of turmoil, the physiology of the body (specifically the brain) was ignored by the psychologists; accordingly, the important developments in the brain's electrophysiology were not taken into consideration. Admittedly, this obliviousness was not only on the part of the pychologists. Neuroscientists did not consider the developments in psychology, either. As a result, the findings and hypothetical formulations that the experimentally oriented psychologists provided were not taken advantage of.

\subsection{An essential step toward oscillatory dynamics: Berger and Adler}

As psychology was coming to the end of schools era, biological sciences were on the pathway to the discovery of the electrical activity of the brain. Several scientists deserve the rank of being the founders of electroencephalography (EEG). Caton (1875; Haas, 2003) obtained electrical recordings from the animal (monkey) brain and noted increased electrical activity during sleep and visual stimulation. Beck (1890) and Vladimir Pravdich-Neminsky (1913; Brazier, 1973) introduced newer elements to the nature of the electrical brain activity: Next to the spontaneous fluctuations, they found the evoked potentials and the desynchronization of the brain waves (for a review, see Coenem, Fine \& Zayachkivska, 2014). Napoleon Cybulski and Jelenska-Macieszyna made the first photographic recordings of the movement of a galvanometer and thus objectively studied changes in EEG during experimentally induced seizures. 
Berger (1929), however, was the first to record EEG from the scalp of humans. He developed the technique of electroencephalography (EEG) and discovered the spontaneous alpha wave (also called the Berger's wave) in the eyes-closed condition and its suppression (alpha blockade) in the eyes-open condition. Alpha reduction in the blockade allowed recognition of the beta waves. Berger also studied the spontaneous EEG alterations in brain diseases, such as epilepsy.

Berger was also a believer in a psychic phenomenon, namely telepathy. For him, EEG was a means for studying telepathy (a mental phenomenon) based on the brain's spontaneous activity (a physical phenomenon). During his time, such an interest was evidently not the spirit of the time (or the zeitgeist). According to Walter (1953, p. 54), Berger, in 1935, was not regarded by his associates as in the "front rank of German psychiatrists, having rather the reputation of being a crank". Moreover, "He had one fatal weakness. He was completely ignorant of the technical and physical basis of his method. He knew nothing about mechanics or electricity". The technique and the findings of Berger were recognized only after other renowned scientists (Adrian \& Matthews, 1934) confirmed the work. The international acknowledgement of EEG activity and the technique of EEG came at a forum held in 1937.

Nearly a decade later, Adrian (1942) found that odorous stimuli produced trains of sinusoidal oscillations in the mucosa of the hedgehog. The oscillations were within the gamma band. Adrian's discovery of the gamma oscillation showed that there is more to the brain oscillations than just the alpha or the beta waves. In the meantime, the alpha oscillation was not faring too well. Neuroscience literature was dominated by such statements as, "Alpha oscillations represent smoke or idling of the brain." and even the statement, "Alpha is noise" (for a review see Başar, 1980). As a result, most oscillation-related studies became focused on mainly the gamma band. Interest in brain oscillations peaked in the 1940s, and thereafter the excitement gradually waned and stabilized at a plateau between the 1950s and the 1980s (for reviews, see Başar, 2012, 2013; Güntekin \& Başar, 2014, 2015).

\subsection{The emergence of a new paradigm in the brain sciences}


Berger's alpha and beta activity were in the form of "spontaneous" oscillations. However, if the electrical activity is a type of brain "behavior," studies should be focused on not only the spontaneously occurring oscillations, but also on the oscillations that occur in response to environmental (external or internal) stimuli. Such an approach is indispensable, given that positivistic science seeks causality between the stimulus as the independent variable and the response as the dependent variable (Başar \& Özesmi, 1972; Başar \& Ungan, 1973; Freeman et al., 2000). As Berger was the pioneer of studies on the spontaneous oscillations of the brain, Adrian was the pioneer of the studies on the brain oscillations that occur in response to stimuli.

The effect of stimuli was initially studied as "evoked potentials" (EPs) to sensory stimuli and Dawson (1951) was the first person to use the summation technique for obtaining the very low amplitude EP recordings against the large and irregular background activity. Time-domain brain response components to cognitive and task-related stimuli were discovered much later. The first "event-related potential" (ERP) component was P300 (Sutton et al., 1965). The component aroused a great deal of interest, and it has been addressed in some 27,000 articles. A sizable amount of these papers was published in such prestigious journals as Science and Nature (Luck, 2014). ERP studies then boomed. The other early ERP components were the surface-negative slow potential (Hillyard \& Galambos, 1967); short-latency, mid-latency and long-latency components of the auditory evoked potential (AEP) (Picton \& Hillyard, 1974); N100 (Hillyard, et al., 1973); and mismatch negativity (MMN) (Naatanen et al., 1978). For a time, the pursuit of new EP/ERP components and the development of recording and analysis techniques became the focus of interest. Such interest in component discovery and technical development continued well into the 1980s. However, the EP/ERP researchers, many of whom were psychologists, were not aware of the gradual shift toward the brain oscillations.

Circa the 1980s, research on EP/ERPs was waning, and the course of the oscillations was following a steady plateau. The following decade, however, witnessed an upsurge in the research on oscillatory dynamics: Between 1980 and 1990, studies were conducted on the neuro-oscillatory dynamics of in vitro tissue of visceral organs (e.g., stomach, colon, 
vasculature) (Başar, 1976; Başar \& Weiss, 1981) and in vivo brain tissue (Eckhorn et al., 1988; Gray \& Singer, 1989; Jahnsen \& Llinas, 1984). Direct recordings were made from the nervous systems of invertebrates (e.g., aplysia/snail/gastropod) and low vertebrates (goldfish, ray). Deep recordings were made on higher vertebrates (e.g., cat, rat, monkey) (for reviews, see Başar, 1980, 2011; also see Dudkin et al., 1978; Silva et al., 1991). Studies on humans began toward the end of the decade. The research of this decade was marked by being precognitive, and the focus of interest was mainly the neuro-oscillatory potentials obtained in response to sensory stimuli (for a review see Başar, 1988; also see Galambos et al., 1981). Nonetheless, 1980-1990 was a flourishing decade, and shortly after its closing, Mountcastle (Başar \&Bullock, 1992, p. xviii) stated: "Rather suddenly, a paradigm shift is upon us, for the proposition that slow wave events are active ingredients for signal transmission stands as a testable hypothesis." Brain oscillations then became a conceptual and analytical tool for potentially understanding cognitive processes (for reviews, see Karakaş \& Başar, 2006a, b; Mountcastle, 1998).

\section{Explanations provided by the oscillatory dynamics: principles and theories}

EEG was acknowledged as a scientific phenomenon in 1937. A paradigm shift involving the study of cognition on the basis of EEG was announced in 1992, and 24 years has passed since. The total period of 79 years has witnessed the accumulation of an immense amount of data on the neuro-oscillatory dynamics of almost all aspects of cognitive processing (Bernat et al., 2007; Besle et al., 2011; Cravo et al., 2013; Gomez-Ramirez et al., 2011; Henry \& Obleser, 2012; Ishii et al., 2009; Jones et al., 2006; Kösem et al., 2014; Stefanics et al., 2010). Such findings have led to generalizations; the experimentally tested generalizations have led to principles that describe the way the universe operates; principles have eventually led to theories, which explain why the universe operates as it does (Başar 1976, 1980, 1998, 1999, 2011; Karakaş \& Başar, 2006a, b). This section presents the principles of neuro-oscillatory dynamics and provides a representative, but by no means an exhaustive, account of research findings that demonstrate the formulations.

Principle 1. Spontaneous EEG is composed of a set of oscillatory components. 
Spontaneous activity and its timing (the various rhythms) is the fundamental organizer of neuronal information and is the source of the cognitive processes (Buzsaki, 2009). Inherent in the concept of neuro-oscillatory dynamics is the assumption that complex brain signals are composed of oscillations of various frequency ranges. Early research was thus devoted to the discovery of the frequency bands in the EEG. The basic technique for showing the frequency composition of a complex time-domain waveform has originally been and is still the fast Fourier transform (FFT). This technique performs power spectral analysis of the EP/ERP waveform. The cut-offs for the frequency bands in the power spectrum are used for adaptive digital filtering and for decomposing the EP/ERP waveform into its frequency components.

The other techniques include those of systems theory, and the techniques specific to living systems (e.g., time series analysis, application of pharmacological agents, ablation, going out of the system) (Başar, 1976; Güntekin \& Başar, 2015). Wavelet analysis, a time-frequency analysis technique, is used for overcoming the Heisenberg uncertainty principle and the resolution problem (Kolev et al., 1997; Mousavi et al., 2014). A relatively recent Wigner-based timefrequency analysis technique, the time-frequency component analyzer, localizes the oscillatory components in the time-frequency domain without cross-term interference and without an assumption of system linearity (Özdemir et al., 2005).

Research that uses the various frequency decomposition techniques has found that the spontaneous activity (EEG) consists of oscillatory components of various frequency ranges (for recent reviews, see Başar, 2012, 2013; Başar \& Güntekin, 2012; Güntekin \& Başar, 2015). The major oscillatory components and the conventionally accepted frequency ranges are as follows: delta (0.5-3.5 Hz), theta (4.0-7.5 Hz), alpha (8.0-13.5 Hz), beta (14.0-29.0 Hz) and gamma (30.0$70.0 \mathrm{~Hz}$ ). Each of these bands and their cognitive correlates have been extensively addressed in different review articles (Başar, 2012, 2013; Güntekin \& Başar, 2014, 2015; Harmony, 2013; Knyazev, 2012). Recent studies (Wen \& Liu, 2016) indicate that EEG is composed not only of rhythmic oscillatory but also of arhythmic fractal components, which deserve future attention. 
Principle 2. The brain responds with oscillatory activity.

Insert Table 2 about here.

Currently neuroscientists (Makeig et al., 2016) tend to think that the oscillatory responses fall on one continuum, ranging from strong to weak phase-locking. For decades, however, literature discriminated three basic categories of electrophysiological brain responses: evoked, event-related and induced (Table 2). The evoked oscillations (EOs) are elicited by sensory stimuli. They are strictly time-locked and phase-locked to the eliciting stimuli. The event-related oscillations (EROs) are emitted by the organism. The experimental paradigm of ERO studies does include stimulation. Unlike the EO, the ERO is not specifically determined by the characteristics of extrinsic stimuli. The neuro-oscillatory dynamics of the ERP is largely determined by intermediary cognitive processes. For example, the oscillatory responses to a series of target stimuli within frequent non-target stimuli are very different when the participant is asked to make a response to the targets (active oddball paradigm: OB-a) than when the participant is asked to ignore them and perform an irrelevant task (passive oddball paradigm: OB-p) (Karakaş et al., 2000). Due to the cognitive impact, ERO components of the oddball paradigm are not strictly time-locked to the stimuli, and their phase angle at the moment of stimulation may show variations.

The third type of EEG response that the relevant literature discusses is the induced oscillations (IOs; for a review see Başar \& Bullock, 1992). IOS are initiated by stimuli but are not tightly coupled to them (Adrian, 1942; Freeman, 1975; Freeman \& Skarda, 1985). Thus they may largely vary in phase and time (Herrmann et al., 2004). Typical experimental tasks that produce induced oscillations involve stimulus omission (\%). In this task, every fourth acoustic stimulus within a series of regularly occurring acoustic stimuli is omitted. The human participant is asked to predict the time of occurrence of the omitted stimulus; make a motor response at the time point when the stimulus should have occurred; and try to mentally imagine the stimulus at the 
very time point. In the omission task, conditions are not conducive to EOs (response elicitation) or to EROs (response emission). A physical stimulus does not exist, and the experience of a stimulus is totally subjective. In the absence of an objective stimulus, time-locking of the oscillatory components to the time point at which the stimulus should have occurred is naturally low and variable (for a detailed review of the IOs, see Başar \& Bullock, 1992).

Principle 3. Poststimulus oscillatory activity is a function of the prestimulus amplitude and phase angle at the point of stimulation.

According to Principle 1, the spontaneous EEG is composed of a set of oscillatory components, and according to Principle 2 , the brain responds to stimulation with oscillatory activity. The phenomenon underlying the transfer of the natural oscillations in the spontaneous activity to oscillatory components in the poststimulus epoch is entrainment (Başar \& Stampfer, 1985; Schürman \& Başar, 1994). When an oscillation entrains to an input rhythm, its high excitability phase coincides with the input rhythm and amplifies the neuronal response (Schroeder \& Lakatos, 2009). This produces a specific relationship between the spontaneous activity and the brain response (be it evoked, event-related or induced): The prestimulus and poststimulus amplitudes are inversely related (Mathewson et al., 2009; Rahn \& Başar, 1993a, b). In all, stimulation leads to a condition where brain generators become selectively regularized and reorganized (e.g. via phase resetting) (for a review, see Başar, 1980; Makeig et al., 2002).

Due to the pre- and poststimulus relationship, alpha blocking, for example, occurs in only the participants with sustained prestimulus alpha activity (Min et al., 2007). Similarly, when there is no alpha activity in the prestimulus EEG, there is no desynchronization response in the poststimulus epoch (Başar \& Turp-Gölbaşı, 2014; Klimesch et al., 2000; Rahn \& Başar, 1993a, b; Stampfer \& Başar, 1985).

The poststimulus response amplitude is, however, dependent on not only the prestimulus amplitude (see Barry et al., 2000; De Blasio \& Barry, 2013a, b; De Blasio et al., 2013) but also on the phase angle of the oscillation at the moment of stimulation (Barry, 2013; Barry \& De Blasio, 
2012; Barry et al., 2003, 2004, 2006, 2007, 2009, 2010, 2014). Accordingly, event-related desynchronization (ERD) is modified by not only the prestimulus amplitude but also by the phase angle of the alpha response (Remond \& Lesevre, 1967). Upon stimulus omission (omitted stimulus paradigm), delta and theta oscillations show phase-ordering (Başar et al., 1984). In the Min et al. study (2007), participants without observable prestimulus alpha activity showed an increase in phase-locked and non-phase-locked activity.

The prestimulus amplitude and the phase angle of the oscillations correlate with individual differences. In a stimulus expectation paradigm, high confidence ratings co-occurred with the negative-going phase of the delta oscillation and this predicted the behavioral reaction times (Stefanics et al., 2010). There was an interrelation between the phase of the delta response, the cognitive outcome, and the phase of the beta response (Fiebelkorn et al., 2013). Delta phase angles resulting in high visual detection were associated with the phase of the $25-\mathrm{Hz}$ beta response; delta phases resulting in low target detection, on the other hand, were associated with the phase of the $35-\mathrm{Hz}$ beta response.

Principle 4. The temporally occurring brain response is a consequence of the superposition of different oscillatory components.

Early research suggested that different peaks on the EP waveform are not differentially associated with different structures or different functions; accordingly, the lack of a given EP peak does not demonstrate that a specific structure has ceased responding or that a specific function has ceased to exist (Başar \& Ungan, 1973). Later research, which covered a spectrum of species and used diverse experimental tasks, found that the temporally occurring waveform signal can be decomposed into oscillatory components (for reviews, Başar, 1980, 1998, 1999) and the original time-domain waveform can be reconstructed from the oscillatory components, leaving a negligible residual (Özdemir et al., 2005). Given that the temporal superposition of the oscillations reliably produces the time-domain peaks, time-domain waveforms should be 
analyzed into their oscillatory components. Principle 4, accordingly states that the analytical units in the complex waveforms is the oscillation of the brain.

Insert Figure 1 about here.

In cognitive neuroscience, research on the superposition patterns of information processing operations and brain functions is steadily increasing. The contributions of the delta and theta oscillatory responses to the P300 component of the oddball response have been well documented (Figure 1). Cognitively, the OB-a paradigm requires stimulus discrimination and working memory. Such a cognitive state is represented by a high amplitude delta response superimposed on the positive-going arm of the theta oscillation. In the OB-p paradigm, selective attention is directed elsewhere. Such a cognitive state is represented by a lower amplitude delta response and the lack of a contributory theta component.

Cognitive load increases the latency and amplitude of the P300 ERP component (Pinal et al., 2014). Cognitive load is also represented by a specific superposition pattern of the delta and theta oscillations at the P300 latency. In this superposition pattern, the positive-going arm of the delta oscillation is in phase with the second positive-going arm of the theta oscillation (Güntekin \& Başar, 2014; Karakaş et al., 2000). Depending on the experimental conditions, the P300-specific delta and theta may further be superimposed by the alpha (Demiralp et al., 1999) and gamma band oscillations (Başar-Eroğlu \& Başar, 1991; Karakaş et al., 2001).

Under appropriate experimental designs, the P300 appears in a bimodal form. The earlier P3a is hypothesized to be an attention-driven response to novelty. Being an orientation response, P3a may be an inborn phyletic response. The later P3b peak is hypothesized to be an index of stimulus evaluation and working memory (Polich, 2007). An analysis of the P300 complex with the S-transform in the time and frequency domains revealed that the theta oscillation contributes to the smaller P3a component, and the larger delta oscillation contributes to the 
larger P3b component (Jones et al., 2006). Kolev et al. (1997) also indicates that P3b is comprised mainly of the delta oscillation. The findings of Prada et al. (2014), however, were exactly the opposite. They found that the delta oscillation contributes to the novelty P3a, and the theta oscillation contributes to the target-related cognitive P3b. These conflicting findings point to the necessity of a validation study on P3a and P3b ERP components because any research on the neuro-oscillatory dynamics of these subcomponents can be justified only if the P300 components in question are valid (see Barry et al., 2016, for a recent clarification of the P300 sub-component complexity).

Among other examples, the superposition of the oscillatory components in the formation of feedback negativity and error-related-negativity (Bernat et al., 2005; Hall et al., 2007), and in the N200 and P300 of the go/no-go task (Harper et al., 2014), can be cited. The selective superposition of the upper alpha and theta oscillations in episodic and semantic memories has also been documented (Klimesch et al., 1994).

Principle 5. There are multiplicities with regard to oscillations and functions.

Oscillatory dynamics display two types of multiplicities in oscillatory dynamics: (1) a single natural frequency may have multiple cognitive functions (multiplicity of function), and (2) a single cognitive function may be represented by multiple frequencies (multiplicity of oscillations).

Principle 5a. Each oscillation has multiple functions.

This type of multiplicity is possible because oscillatory components are defined (measured), not only with respect to frequency, but also in relation to the following oscillation-related parameters: enhancement, attenuation, blocking, duration (prolongation), latency, timelocking, phase-locking and frequency-locking of the oscillations. The other critical factors that alter the functional meaning of an oscillation are the topology that the oscillation is recorded from, the coherence function between different neural structures with respect to the different oscillatory components, the developmental level of the subject, and the species from which the 
oscillation is obtained. The number of combinations that can be formed by all these variables can potentially handle many of the processes currently studied in cognitive neuroscience.

Multiple functions of the alpha oscillation. Evoked alpha is functional at not only the organismic but also the cellular level (for a review, see Başar, 2012; Creutzfeldt et al., 1966). Topographically alpha band activity represents sensory functions when recorded from sensory areas (for a review, see Başar, 1998, 1999) and motor responses when recorded from areas involved in voluntary motor control (Pineda, 2005). High-amplitude, regular alpha waves that are recorded from the occipital cortex represent relaxed wakefulness (resting condition). High cognitive load is represented by prolonged alpha oscillations at the frontal cortex (for a review, see Başar 2012; Öniz \& Başar, 2009). Alpha phase-locking represents task complexity (Kanizsa versus non-Kanizsa figures), and the total alpha reflects memory demands (Herrmann et al., 2004). Developmentally, activity in the alpha frequency range appears in preschoolers after three years of age (Figure 2) (Başar, 2012).

Insert Figure 2 about here.

The alpha oscillation correlates with affective processing. High occipital alpha power coupled with frontal beta is obtained when participants view angry faces in contrast to happy ones (Güntekin \& Başar, 2007). Davidson et al., (1979) found hemispheric specificity of the alpha oscillatory component in only the spontaneous activity. Positive affect was represented by a greater alpha in the left hemisphere, whereas negative affect was represented by a greater alpha in the right hemisphere. Alpha power represents anxiety (Knyazev et al., 2006). The amplitude of the phase-locked alpha response and the ERD is higher in high-anxiety subjects.

With all the variations under almost all aspects of cognitive processing, alpha is considered to be an important signal in the neural basis of cognition. Accordingly, alpha has been described as 
a universal code, a universal operator, a building block of dynamic processes and quasiinvariants in brain-body-mind integration (for reviews, see Başar 2012; Başar \& Güntekin, 2012; Başar et al., 1997).

Multiple functions of the gamma oscillation. According to a large number of publications, gamma is considered to be an important oscillation in brain signaling (for a review, see Başar, 2013). Intensive research has associated gamma oscillations with perceptual processes. According to Singer \& Gray (1995), perception is represented by the gamma band response; the authors hypothesized that gamma band activity binds stimulus features into coherent percepts. Supporting this statement, long-distance in-phase synchrony is observed in the gamma band during pattern recognition (Rodriguez et al., 1999). However, long-distance functional connectivity increases occur in the gamma band during not only perception but also attention, memory, and learning (Desimone, 1996). Significantly, there are many different gamma band synchronizations, and each one serves different functions (Fries, 2009). Furthermore, perception is more than a mere binding of stimulus features; top-down influences pertaining to prior experiences, motivations, emotions, attitudes, values, and, in short, everything about the mind, affects how a specific pattern of features will be perceived (Freeman, 1991; Goldstein, 2014). According to the dynamicist view (Engel et al., 2001), this top-down influence acts as an intrinsic source of contextual modulation of the temporal structure of both the spontaneous activity and the response potentials.

Gamma responses are obtained at different time windows. The gamma band response which is obtained with strong time-locking and phase-locking within the 150-ms poststimulus time window represents sensory processing. Accordingly, the early gamma response is basically an EO (Herrmann et al., 2004; Fell, Hinrichs T\& Röschke, Karakaş et al., 2001). Gamma obtained as an EO to task-relevant faces (famous or nonfamous), on the other hand, is weaker and the selective connectivity between various brain structures is lower than that for the gamma obtained as an ERO (Engell \& McCarthy, 2010; Özerdem et al., 2011). 
Meanwhile, the gamma response at the later 250-350 ms time window shows weak time- and phase-locking (Fell et al., 1997; Herrmann et al., 2004). However, deep recordings from the HI3 layer of the cat brain reveal a strong $\mathrm{P} 300-40 \mathrm{~Hz}$ complex, which is obtained in response to stimulus omission (Başar-Eroğlu \& Başar, 1991). Performance in the stimulus paradigm is dependent on memory. These findings are very much in line with the role of the hippocampus in retrieval of episodic memory (for a review, see Buzsaki, 2006). Early research had indicated that the late gamma response is related to higher cognitive processing (Başar-Eroğlu et al., 1996a; Karakaş \& Başar, 1998).

The gamma response shows individual differences; there are gamma responders and nonresponders to the oddball paradigm condition (Karakaş et al., 2003). Gamma response is involved in affective processing. In contrast to happy or neutral expressions, angry expressions produce higher amplitudes (Güntekin \& Başar, 2007, 2010; Keil et al., 2001; Martini et al., 2012; Müller et al., 1999). The gamma response that is obtained in affective processing starts early and extends up to $850 \mathrm{~ms}$ (for a review, see Güntekin \& Başar, 2014). A rapid response to anger-evoking stimuli has an adaptive value and thus contributes to the survival of organisms.

Finally, gamma rhythm is demonstrated in long-distance neural pathways with selective coherences between cortical and subcortical brain structures; neuronal synchronization in the gamma band serves as an agent for attentional processing and memory (Jensen \& Colgin, 2007; Jensen et al., 2007). All of these functions may justify the description of the gamma response as another "universal operator" of brain functioning (Başar, 1980; Başar-Eroğlu et al., 1996b; Fries, 2009).

Multiple functions of the delta oscillation. A delta response recorded from the frontal regions represents cognitive processing (for a review, see Güntekin \& Başar, 2015). When recorded from the parietooccipital locations, delta response represents cognitive and affective processing of faces (Balconi \& Lucchiari, 2006; Güntekin \& Başar, 2009; Sakihara et al., 2012). The delta response amplitude is higher for photographs of loved ones than for photographs of 
unfamiliar faces or unfamiliar but appreciated faces (Başar et al., 2008). In contrast, it is higher for angry or happy faces in comparison to neutral ones (Knyazev et al., 2009). Of the two components of affective processing, the slower delta and theta oscillations represent arousal, whereas the faster beta and gamma oscillations represent valence (quality) (Güntekin \& Başar, 2014).

Principle 5b. Each cognitive function is represented by multiple oscillations.

The foregoing findings show instances in which a given oscillation performs multiple functions. In the second type of multiplicity, a given function is represented by multiple oscillations. This type of multiplicity is, in fact, a direct consequence of Principle 4, according to which oscillations of different frequencies are integrated on the time axis. A functional time-domain component such as the P300 is a result of selectively superimposed oscillatory bands at the latency of the component. A cognitive function, such as working memory, is represented by the P300 ERP component. The shape of this component can be decomposed into the specified oscillatory components and, in turn, be reconstructed from them (Karakaş et al., 2000, 2001). During anxiety, delta and beta show high coupling in spontaneous EEG (Knyazev et al., 2006), and this is inversely related to testosterone level (Miskovic \& Schmidt, 2009) and directly related to cortisol level (Schütter \& van Honk, 2005).

An interim summary would be as follows: the brain and mind are the most complex systems in the universe. In the challenging task of understanding how the brain operates in cognitive processing, the pattern emerging from the superposition of multiple oscillations should be studied in at least the whole cortex. A major task of cognitive neuroscience should be to discover specific patterns of oscillatory activity that serve as "fingerprints" of cognitive functions.

\section{Principle 6. Oscillations are spatially integrated.}

Many theories and models have attempted to explain cognition (Anderson, 2014; Goldstein, 2010; Sternberg, 2006). The early or the late serial models of information processing no longer 
have satisfactory explanatory value. According to the parallel distributed processing (PDP) model, information processing is achieved through a large number of processing elements. The connections between the elements can be active at the same time, and this enables the system to manipulate a large number of cognitive operations all at once (McClelland et al., 1986). Contemporary theories on brain function are based on the PDP model (for a review, see Karakaş \& Başar, 2006a, b). Examples include that of Goldman-Rakic (1988) on parallel sensorycognitive processing, Mesulam (1990) on distributed processing in large-scale neurocognitive networks, and Fuster (1995) on cortical memory. All of these PDP theories are based on neuroanatomy. In Başar's $(1998,1999,2011)$ whole-brain work, PDP is based on brain oscillations. In this theory, the critical factors in sensory-perceptual and cognitive functions are specific patterns of oscillatory superpositions and specific patterns of neural connectivity (Başar et al., 2014).

According to the previous principles of oscillatory dynamics listed above, each frequency is used in the brain to perform not just one but multiple functions. In turn, each function is represented by multiple oscillations. Superposition produces a temporal integration and a synergy among the natural frequencies (delta, theta, alpha, beta and gamma). A second type of integration and synergy occurs spatially. According to Principle 6, functions are characterized by specific connectivity patterns between neural structures and the oscillations they generate.

Coherence and its nature have been studied by various researchers. The framework of Bastos, Vezoli and Fries (2015) on communication through coherence, the groundbreaking work of Rubinov and Sporns (2010) on net connectivity and its potential relation to cognitive states, and the theoretical work of Buszaki (2009) are a few of these studies. Jensen and Colgin (2007) suggest that neuronal synchronization in the gamma band is directed to task-relevant networks, while task-irrelevant networks are blocked via the alpha activity. The theory of whole-brainwork (Başar, 1998, 1999) also deals with Principle 6. According to the theory, there are selectively coherent neural populations that are selectively distributed in the brain (Başar, 
1980). The distributed oscillations are highly integrated; they produce supersynergy in the brain, leading to a holistically functioning brain in cognitive processing.

\section{Current Status and Prospects}

A large amount of data has been generated on neuro-oscillatory dynamics since 1992, which is the date when Mountcastle (1998) defined the new paradigm of neuroscience as "oscillatory dynamics". These findings were obtained from a large spectrum of species in different developmental levels, covered from sensory to cognitive functions, included spontaneous activity along with evoked, emitted, and induced responses, and covered all of the natural frequencies of the nervous system. The findings were replicated and confirmed, and a formulation of principles of neuro-oscillatory dynamics became possible. Finally, models and theories were proposed on the neuro-oscillatory dynamics of the brain in cognitive processing (for a review, see Başar et al., 2001; Karakaş \& Başar, 2006a, b). These developments justify the conclusion that oscillatory potentials can be helpful in understanding the brain correlates of cognitive-affective processes and, by this approach, the very processes themselves. The brain oscillations may provide a key to such intriguing questions as "How are sensory modalities integrated?", "How does feature selective attention modify perceptual representations" and "How do the different psychological processes operate?"

In closing, the present paper examines two issues. One of the issues addresses the utility of neuro-oscillatory dynamics in understanding neuropsychiatric disorders, and in providing biomarkers for diagnosis and monitoring disease progression (Başar et al., 2013). The other is the present status of the science of psychology in the study of the mind-brain (body) relationship and oscillatory dynamics.

\subsection{Neuro-oscillatory dynamics in neuropsychiatric disorders}

Currently, the level that basic science has reached on neuro-oscillatory dynamics justifies its application to different areas; the foremost of which is neuropsychiatric disorders. Research on neuropsychiatric disorders uses two main approaches. (1) The basic science approach, in which 
the etiology of the disorder is investigated. A defined neuropsychiatric disorder is, in fact, a convenient counterpart of the experimental ablation technique in the biological systems analysis program (Başar, 1976; Güntekin \& Başar, 2015). (2) The applied science approach to the disorder, in which research is focused on diagnosis, disease progression, and rehabilitation. The following discussion applies the foregoing principles of neuro-oscillatory dynamics to a selected neuropsychiatric disorder, the Alzheimers disease (AD). The section is a demonstration of the applicability of the principles that have been derived from normal populations to a population with a neuropsychiatric disorder.

In line with Principles 1 and 2, $A D$ cases display all natural frequencies in both their spontaneous (EEG) activity and their brain response. According to Principle 3, prominent poststimulus components are dependent on the extent of EEG power- and phase-locking. Lowpower and strong phase-locking are predictors of high amplitudes in the poststimulus oscillatory activity (Mathewson et al., 2009; Rahn \& Başar, 1993a, b). In the AD group, spontaneous activity in the high-frequency (beta and gamma) bands is particularly low over the occipito-parietal areas (Vecchio et al., 2013). A prediction from Principle 3 would specify that high amplitudes would be obtained in the high-frequency responses of the poststimulus epoch. Indeed, sensorial gamma response amplitude of the AD group is comparable to that of healthy controls (Haupt et al., 2008; Van Deursen et al., 2011; Yener \& Başar, 2013). In line with this finding, sensory-evoked coherences are comparable to those of the healthy controls in all frequency ranges. Meanwhile, in all frequency ranges, event-related coherences are decreased in the AD group (Yener \& Başar, 2010, 2013).

The occipito-temporal spontaneous activity of AD patients displays increased power in the lowfrequency (delta and theta) bands (Vecchio et al., 2013). Principle 3 predicts low delta and theta response amplitudes and weak phase-locking. The low phase-locking of the theta oscillation is in line with this principle (Figure 3). However, the amplitude data are contrary to the prediction from Principle 3: the $A D$ group displays increased amplitudes and hyperactivity in the theta range over the primary and secondary sensory areas and the motor areas (Ferreri et al., 2003). 
In this group, the evoked theta over the occipito-parietal area (the dorsal stream) is also increased (Yener \& Başar, 2013; Yener et al., 2007, 2009). These findings suggest that both object perception and visuo-spatial perception are markedly different from that of healthy controls (Ungerleider \& Haxby, 1994; Ungerleider \& Mishkin, 1982).

Insert Figure 3 about here.

In the delta frequency range, the $A D$ group displays decreased coherences between the sensory/perceptual areas and the frontal areas. Although primary sensory processing and visuospatial processing may be functional in AD (Yener et al., 2008, 2012), the frontal integration of visuo-spatial perception (dorsal pathway) and object perception (ventral pathway) are evidently negatively affected (Başar, 2010; Güntekin et al., 2008). The coherence decrease involving the frontal areas was not only specific to sensory/perceptual areas. Event-related coherences between the frontal area and all the other brain areas were also decreased; this effect was observed in all the lower frequency bands. Overall, the ordering of the oscillatory components on the time axis is disorganized (Principle 4), and the spatial integrity is degraded (Principle 6). The violation of Principle 6 results in an impaired integrity between sensory-perceptual functions and frontal executive functions (Başar et al., 2010). These findings on the highfrequency spontaneous oscillations, response amplitudes, and coherence decrease in selected brain areas point to a set of biomarkers for AD.

Neuro-oscillatory dynamics also suggest criteria for the progression of the disease from the healthy state to mild cognitive impairment ( $\mathrm{MCl}$ ), and finally, to AD (Yener \& Başar, 2013). This progression is represented by (1) a decrease in the amplitude and an increase in the latency of the event-related delta oscillation and (2) by a decrease in the coherence values for EROs in the 
delta, theta and alpha frequency ranges. These findings were obtained from frontal and parietal locations.

According to Başar et al. (2015), the neuro-oscillatory dynamics of the normally functioning human brain become "broken" in neuropsychiatric disorders. In AD, the brain no longer obeys the principles of oscillatory dynamics, and paradoxes or inconsistencies arise. Briefly, the list of natural frequencies become shorter; delta oscillations attenuate to insignificant levels (cf. Principle 1); evoked response functions, but not event-related functions, are preserved (cf. Principle 2); low spontaneous delta is coupled with low event-related delta ( $c f$. Principle 3); altered oscillatory integration over the time axis occurs due to a disappearance of some of the oscillatory components (Principal 4); and functions become "broken" such that components of sensory-perceptual processing are preserved, but their integration is not (cf. Principle 6).

Determining what constitutes a normal brain is a necessary step, but it is not sufficient for understanding what occurs in a brain afflicted with a neuropsychiatric disorder. According to the foregoing, functions of a diseased brain do not exactly obey the principles of oscillatory dynamics. Regarding brain plasticity and its compensatory functions, are we scientists confronted with the task of finding a set of principles for each disorder? Is this the message that the nebulous Cartesian system of the brain-body-mind relationship is trying to convey to us (Başar, 2011)?

\subsection{Neuro-oscillatory dynamics in the psychological sciences}

In the beginning, as with all the disciplines, psychology was in the realm of philosophy. Then Wundt (1896) emancipated it from the mother field and established the "new experimental psychology." The first paradigm shift in psychology was thus its transition from a philosophical discipline to a scientific field. Throughout the 19th century, psychologists made it their mission to analyze consciousness into its components (structuralism); to investigate the goal-oriented, adaptive behavior (functionalism); to determine the antecedent conditions of behavior (radical behaviorism); to understand the dynamics of the unconscious and its influences on the 
cognitive-affective processes and behavior (psychoanalysis). Then came "liberal behaviorism", where the mission was to study the cognitive correlates of behavior. This school paved the way for the cognitive revolution (Miller, 1956; Neisser, 1967). With the cognitive revolution, psychologists started studying the black box between the stimulus and response. However, psychological studies were still behavioral. Black box processes were not directly observed, but inferred from behavior using complex research designs, and advanced statistical techniques (Karakaş \& Başar, 2006a, b).

Although the science of psychology that Wundt founded was a "physiological psychology" (Wundt, 1874), psychologists (even Wundt) ignored the body/brain component of the intact organism until the 1930s, and instead chose to study the mind from many different perspectives (i.e., soul, conscience, unconscious, behavior, cognition). It was during the second part of the $20^{\text {th }}$ century that psychologists started studying brain activity (Sutton et al., 1965). For the better part of the $20^{\text {th }}$ century, psychologists tried to discover the ERP components and explain their cognitive meanings. The interest in discovering ERP components gradually faded towards the end of the century, and the announcement at the closing of the century of the new paradigm of cognitive neuroscience was not highly regarded.

A literature search of PubMed shows the extent to which psychologists who work in psychology departments presently consider the issue of brain-referenced cognitive-affective processes. Of all the ERP publications that were included in PubMed, only 7.1\% (8917/124272) bear the address of a psychology department. Of the studies that employ functional magnetic resonance imaging, only $0.88 \%$ (20/31609) include the address of a psychology department. The percentage for oscillatory potentials is $0.06 \%$ (354/401892).

Meanwhile, the investigation of the organismic correlates of cognitive-affective behavior should be resting heavily on the shoulders of psychologists. However, psychologists in the psychology departments are generally satisfied by studying behavior and inferred cognition. The tremendous focus on multidisciplinary cognitive science is presently shared by scientists coming 
from biological and technical branches, and psychological research is conducted at institutions that do not bear the term. Cognitive neuroscience is still awaiting the active contribution of those psychologists who work in psychology departments toward the advancement of knowledge on the organismic correlates of cognitive-affective processes, and for the application of the brain-based approach to psychological phenomena.

\section{Limitations}

The present paper provides a brief historical perspective on the historical evolution that has led to the study of the brain (body)-mind relationship based on brain oscillations. Based on 180 references, the paper aims to trace the historical background of the present status of the oscillatory components in cognitive neuroscience. It traces the major developments that have led to the escalation of empirical data on the brain oscillations to principles and theories. Space limitations obviously prevent the provision of information on the oscillatory representation of each and every cognitive process that cognitive psychology provides, an account of the mechanisms by which the brain regions communicate with each other, and the biophysical origins and mathematical properties of neural oscillations. We also cannot include recent important developments and a comparison of the existing models and theories on oscillatory dynamics (see Herrmann et al., 2016 for a recent review).

In brief, the present paper cannot exhaust all the relevant issues on the topic of oscillatory dynamics. However, our treatise on the advent of brain oscillations in the biological and psychological disciplines may provide a foundation for future works that go deeper into the historical milestones and the recent developments in this field.

\section{References}

1. Adrian, E.D., 1942. Olfactory reactions in the brain of the hedgehog. J. Physiol. 101, 459473.

2. Adrian, E.D., Matthews, B.H.C., 1934. The berger rhythm: potential changes from the occipital lobes in man. Brain, 57, 355-385. 
3. Anderson, R., 2014. Cognitive Psychology and Its Implications, fifth edition. Worth Publishing, New York.

4. Balconi, M., Lucchiari, C., 2006. EEG correlates (event-related desynchronization) of emotional face elaboration: a temporal analysis. Neurosci. Lett. 392(1-2), 118-123.

5. Barry, R.J., 2013. Preferred pre-stimulus EEG states affect cognitive event-related potentials. Clin. Neurophysiol. 62, 55-65.

6. Barry, R.J., De Blasio, F.M., 2012. EEG-ERP phase dynamics of children in the auditory Go/NoGo task. Int. J. Psychophysiol. 86, 251-261.

7. Barry, R.J., De Blasio, F.M., De Pascalis, V., Karamacoska, D., 2014. Preferred EEG brain states at stimulus onset in a fixed interstimulus interval equiprobable auditory Go/NoGo task: A definitive study. Int. J. Psychophysiol. 94, 42-58.

8. Barry, R.J., De Blasio. F., Rushby, J.A., Clarke A.R., 2010. Brain dynamics in the auditory Go/NoGo task as a function of EEG frequency. Int. J. Psychophysiol. 78, 115-128.

9. Barry, R.J., De Pascalis, V., Hodder, D., Clarke, A.R., Johnstone, S.J., 2003. Preferred EEG brain states at stimulus onset in a fixed interstimulus interval auditory oddball task and their effects on ERP Int. J. Psychophysiol. 47(3), 187-98.

10. Barry, R.J., Kirkaikul, S., Hodder, D., 2000. EEG alpha activity and the ERP to target stimuli in an auditory oddball paradigm. Int. J. Psychophysiol. 39, 39-50.

11. Barry, R.J., Rushby, J.A., Johnstone, S. J., Clarke, A.R., Croft, R.J., Lawrence, C.A., 2004. Event-related potentials in the auditory oddball as a function of EEG alpha phase at stimulus onset. Clin. Neurophysiol. 115, 2593-2601.

12. Barry, R.J., Rushby, J.A., Smith, J.L., Clarke, A.R., Croft, R.J., 2006. Dynamics of narrowband EEG phase effects in the passive auditory oddball task. Eur. J. Neurosci. 24(1), 291304.

13. Barry, R.J., Rushby, J.A., Smith, J.L., Clarke, A.R., Croft R.J., 2009. Brain dynamics in the auditory oddball task as a function of stimulus intensity and task requirements. Int. J. Psychophysiol. 73, 313-325.

14. Barry, R.J., Rushby, J.A., Smith, J.L., Clarke, A.R., Croft, R.J., Wallace, M.J., 2007. Brain dynamics in the active vs. passive auditory oddball task: Exploration of narrow-band EEG phase effects. Clin. Neurophysiol. 118, 2234-2247.

15. Barry, R.J., Steiner, G.Z., De Blasio F.M., 2016. Reinstating the Novelty P3. Sci. Rep. 6, 31200; doi: 10.1038/srep31200.

16. Bastos, A.M., Vezoli, J., Fries, P., 2015. Communication through coherence with interareal delays. Curr. Opinion Neurobiol. 31(0), 173-180.

17. Başar, E., 1976. Biophysical and Physiological Systems Analysis. Addison-Wesley, Reading, Amsterdam.

18. Başar, E., 1980. EEG-Brain Dynamics. Elsevier, North Holland.

19. Başar, E. (Ed.), 1988. Dynamics of Sensory and Cognitive Processing by the Brain. Springer-Verlag, London.

20. Başar, E., 1998. Brain Function and Oscillations I. Brain Oscillations. Principles and Approaches. Springer, Berlin.

21. Başar, E., 1999. Brain function and oscillations II. Integrative brain function. Neurophysiology and cognitive processes. Springer, Berlin. 
22. Başar, E., 2010. From "Quantum Mechanics to the Quantum Brain". Neuroquantology, 8, 319-321.

23. Başar, E., 2011. Brain-Body-Mind in the Nebulous Cartesian System: A Holistic Approach by Oscillations, Springer, Berlin.

24. Başar, E., 2012. A review of alpha activity in integrative and brain function: Fundamental physiology, sensory coding, cognition and pathology. Int. J. Psychophysiol. 86(1), 1-24.

25. Başar, E., 2013. A review of gamma oscillations in healty subjects and in cognitive impairment. Int. J. Psychophysiol. 90(2), 99-117.

26. Başar, E., Başar-Eroğlu, C., Karakaş, S., Schürmann, M., (Guest Eds.) (2001). Eventrelated oscillations in perception and memory. Int. J. Psychophysiol. 39, 2-3.

27. Başar, E., Başar-Eroğlu, C., Rosen, R., Schütt, A., 1984. A new approach to endogenous event-related potentials in man: relation between EEG and P300-wave. Int. J. Neurosci. 24, 1-21.

28. Başar, E., Başar-Eroğlu, C., Özerdem, A., Rossini, P.M., Yener, G.G., (Eds.), 2013. Application of Brain Oscillations in Neuropsychiatric Diseases. Supplements to Clinical Neurophysiology (Special Issue), 62.

29. Başar, E., Bullock, T.H., (Eds.) (1992). Induced Rhythms in the Brain, Birkhäuser, Boston.

30. Başar, E., Düzgün, A., Güntekin, B., 2014. A Proposal to extend Brodmann's Areas concept to a new model. NeuroQuantology, 12(2), 201-209.

31. Başar, E., Düzgün, A., 2015. The CLAIR model: Extension of Brodmann's areas based on brain oscillations and connectivity. International Journal of Neuropsychology. 103, 18598.

32. Başar, E., Güntekin, B., 2012. A short review of alpha activity in cognitive processes and in cognitive impairment. Int. J. Psychophysiol. 86(1), 25-38.

33. Başar, E., Güntekin, B., Tülay, E., Yener, G.G., 2010. Evoked and event related coherence of Alzheimer patients manifest differentiation of sensory-cognitive networks. Brain Res. 1357, 79-90.

34. Başar, E., Hari, R., Lopes Da Silva, F.H., Schürmann, M. (Eds), 1997. Brain alpha activity new aspects and functional correlates. Int. J. Psychophysiol. 26, 1-482.

35. Başar, E., Karakaş, S., 2006. Models and Theories of Brain Function with Special Emphasis on Cognitive Processing. International Journal of Psychophysiology. 60(2), 97201.

36. Başar, E., Özesmi, Ç., 1972. The hippocampal EEG-activity and a systems analytical interpretation of averaged evoked potentials of the brain. Kybernetik, 12(1), 45-54.

37. Başar, E., Schmiedt-Fehr, C., Mathes, B., Femir, B., Emek-Savaş, D.D., Tülay, E., Tan, D., Düzgün, A., Güntekin, B., Özerdem, A., Yener, G., Başar-Eroğlu, C., 2015. What does the broken brain say to the neuroscientist? Oscillations and connectivity in schizophrenia, Alzheimer's disease, and bipolar disorder. Int. J. Psychophsiol. 103, 13548.

38. Başar, E., Schmiedt-Fehr, C., Öniz, A., Başar-Eroğlu, C., 2008. Brain oscillations evoked by the face of a loved person. Brain Res. 1214, 105-115.

39. Başar, E., Stampfer, H.G., 1985. Important associations among EEG-dynamics, eventrelated potentials, short-term memory and learning. Int. J. Neurosci. 26(3-4), 161180. 
40. Başar, E., Turp Gölbaşı, B., 2014. Event related desynchronization: use as a neurophysiologic marker is restricted. Cognitive Neurodynamics, 8(6), 437-445.

41. Başar, E., Ungan, P., 1973. A component analysis and principles derived for the understanding of the evoked potentials of the brain: Studies in the hippocampus. Kybernetik, 12, 133-140.

42. Başar, E., Weiss, C., 1981. Vasculature and Circulation. Elsevier, Amsterdam.

43. Başar-Eroglu, C., Başar, E., 1991. A compound P300-40 Hz response of the cat hippocampus. Int. J. Neurosci., 227-237.

44. Başar-Eroglu, C., Strüber, D., Kruse, P., Başar, E., Stadler, M., 1996a. Frontal gamma band enhancement during multistable visual perception. Int. J. Psychophysiol. 24, 113125.

45. Başar-Eroglu, C., Strüber, D., Schürmann, M., Stadler, M., Başar, E., 1996b. Gamma-band responses in the brain: a short review of psycho-physiological correlates and functional significance. Int. J. Psychophysiol. 24, 101-112.

46. Beck A., 1888. O pobudliwości różnych miejsc tego samego nerwu. Rozpr. Wydz. mat.przyr. polsk. Akad. Um. 15, 165-95.

47. Berger, H., 1929. Uber des elektroenkephalogram, Arch Psychiatry Nervenkr, 87, 527570.

48. Bernat, E.M., Malone, S.M., Williams, W.J., Patrick, C.J., lacono, W.G., 2007. Decomposing delta, theta, and alpha time-frequency ERP activity from a visual oddball task using PCA. Int. J. Psychophysiol. , 64, 62-74.

49. Bernat, E.M., Williams, W.J., Gehring, W.J., 2005. Decomposing ERP time-frequency energy using PCA. Clin.Neurophysiol. 116, 1314-1334.

50. Besle, J., Schevon, C.A., Mehta, A.D., Lakatos, P., Goodman, R.R., McKhann, G.M., Emerson, R.G., Schroeder, C.E., 2011. Tuning of the human neocortex to the temporal dynamics of attended events. J. Neurosci. 31, 3176-3185.

51. Boring, E.G., 1950. History of Experimental Psychology. Appleton-Century-Crofts, New York.

52. Brazier, M.A. (Ed.), 1973. Epilepsy: Its Phenomena in Man. New York: Academic Press.

53. Buszaki, G., 2009. Rhythms of the Brain. Oxford Univ. Pr., Oxford (UK).

54. Caton, R., 1875. Electrical currents of the brain. British Medical Journal. 2(765), 278.

55. Coenen, A., Fine, E., Zayachkivska, O., 2014. Adolf Beck: A forgotten pioneer in Electroencephalography. Journal of the History of Neurosciences. 23(3), 276-286.

56. Cravo, A.M., Rohenkohl, G., Wyart, V., Nobre, A.C., 2013. Temporal expectation enhances contrast sensitivity by phase entrainment of low-frequency oscillations in visual cortex. J. Neurosci. 33, 4002-4010.

57. Creutzfeldt, O.D., Watanabe, S., Lux, H.D., 1966. Relations between EEG-phenomena and potentials of single cortical cells. I. Evoked responses after thalamic and epicortical stimulation. EEG Clin. Neurophysiol. 20, 1-18.

58. Davidson, R.J., Schwartz, G.E., Saron, C., Bennett, J., Goldman, D.J., 1979. Frontal versus parietal EEG asymmetry during positive and negative affect. Psychophysiol. 16, 202-203.

59. Dawson, G.D., 1951. A summation technique for detecting small signals in a large irregular background. J. Physiol. (Lond.), 115, 2-3. 
60. De Blasio, F.M., Barry R.J., 2013a. Prestimulus delta and theta determinants of ERP responses in the Go/NoGo task. Int. J. Psychophysiol. 87, 279-288.

61. De Blasio, F.M., Barry R.J., 2013b. Prestimulus alpha and beta determinants of ERP responses in the Go/NoGo task. Int. J. Psychophysiol. 89, 9-17.

62. De Blasio, F.M., Barry, R.J., Steiner, G.Z., 2013. Prestimulus EEG amplitude determinants of ERP responses in a habituation paradigm. Int. J. Psychophysiol. 89, 444-450.

63. Demiralp, T., Yordanova, J., Kolev, V., Ademoğlu, A., Devrim, M., Samar, V.J., 1999. Time-frequency analysis of single-sweep event-related potentials by means of fast wavelet transform. Brain Lang. 66, 129-145.

64. Desimone, R., 1996. Neural mechanisms for visual memory and their role in attention. Proc. Natl. Acad. Sci. USA. 26, 13494-13499.

65. Dudkin, K.N., Glezer, V.D., Gauselman, V.E., Panin, A.I., 1978. Types of receptive fields in the lateral geniculate body and their functional model. Biol. Cybern. 29, 37-47.

66. Eckhorn, R., Bauer, R., Jordan, R., Brosch, W., Kruse, M., Munk, M., Reitboeck, H.J., 1988. Coherent oscillations: a mechanism of feature linking in the visual cortex. Biol. Cybern. 60, 121-130.

67. Engel. A.K., Fries, P., Singer, W., 2001. Dynamic predictions: Oscillations and synchrony in top-down processing. Nature, 2, 704-716.

68. Engell, A.D., McCarthy, G., 2010. Selective attention modulates face-specific induced gamma oscillations recorded from ventral occipitotemporal cortex. J. Neurosci. 30, 30(26), 8780-8786.

69. Fell, J., Hinrichs, H., Roschke, J., 1997. Time course of human $40 \mathrm{~Hz}$ EEG activity accompanying P3 responses in an auditory oddball paradigm. Neurosci. Lett. 235, 121124.

70. Ferreri, F., Pauri, F., Pasqualetti, P., Fini, R., Dal Forno, G., Rossini, P.M., 2003. Motor cortex excitability in Alzheimer's disease: a transcranial magnetic stimulation study. Ann Neurol. 53(1), 102-8.

71. Fiebelkorn, I.C., Foxe, J.J., McCourt, M.E., Dumas, K.N., Molholm, S., 2013. Atypical category processing and hemispheric asymmetries in high-functioning children with autism: revealed through high-density EEG mapping. Cortex; a Journal Devoted to the Study of the Nervous System and Behavior, 49(5), 1259-1267.

72. Freeman, M.A., 1975. Pathogenesis of osteoarthrosis. An hypothesis. Ann. Rheum. Dis. 34 Suppl 2,Suppl 120-1.

73. Freeman, W.J., 1991. The physiology of perception. Sci. Am. 264 (2), 78-85.

74. Freeman, W.J., Rogers, L.J., Holmes, M.D., Silbergeld, D.L., 2000. Spatial spectral analysis of human electrocorticograms including the alpha and gamma bands. J. Neurosci. Methods. 95, 111-121.

75. Freeman, W., Skarda, C., 1985. Spatial EEG-patterns, non-linear dynamics and perception: the neo-sherringtonian view. Brain Res. Rev. 10, 147-175.

76. Fries, P., 2009. Neuronal gamma-band synchronization as a fundamental process in cortical computation. Ann. Rev. Neurosci. 32, 209-224.

77. Fritsch, G., Hitzig, E., 1870. Über die elekrische erregbarkeit des grosshirns. Arch. Anat. Physiol. Wissen. 37, 300-332. 
78. Fuster, J.M., 1995. Memory in the Cerebral Cortex-An Empirical Approach to Neural Networks in the Human and Nonhuman Primate. MIT Press, Cambridge, MA.

79. Galambos, R.S., Makeig, P., Talmachoff, A., 1981. $40 \mathrm{~Hz}$ auditory potential recorded from the human scalp. Proc. Natl. Acad. Sci. USA. 78, 2643-2647.

80. Goldman-Rakic, P.S., 1988. Topography of cognition: parallel distributed networks in primate association cortex. Ann. Rev. Neurosci. 11, 137-56.

81. Goldstein, B., 2010. Cognitive Psychology: Connecting Mind, Research and Everyday Experience with Coglab Manual ( $3^{\text {rd }}$ ed). Wadsword, Belmont.

82. Goldstein, E.B., 2014. Cognitive Psychology: Connecting Mind, Research and Everyday Experience. Canada.

83. Gomez-Ramirez, M., Kelly, S.P., Molholm, S., Sehatpour, P., Schwartz, T.H., Foxe, J.J., 2011. Oscillatory sensory selection mechanisms during intersensory attention to rhythmic auditory and visual inputs: a human electrocorticographic investigation. J. Neurosci. 31, 18556-18567.

84. Gray, C.M., Singer, W., 1989. Stimulus-specific neuronal oscillations in orientation columns of cat visual cortex. Proc. Natl. Acad. Sci. USA. 86(5), 1698-702.

85. Güntekin, B., Başar, E., 2007. Emotional face expressions are differentiated with brain oscillations. Int. J. Psychophysiol. , 64(1), 91-100.

86. Güntekin, B., Başar, E., 2009. Facial affect manifested by multiple oscillations. Int. J. Psychophysiol. , 71, 31-36.

87. Güntekin, B., Başar, E., 2010. Event-related beta oscillations are affected by emotional eliciting stimuli. Neurosci. Lett. 483, 173-178.

88. Güntekin, B., Başar, E., 2014. A review of brain oscillations in perception of faces and emotional pictures. Neuropsychologia, 58, 33-51.

89. Güntekin, B., Başar, E., 2015. Review of evoked and event-related delta responses in the human brain. Int. J. Psychophysiol. 103, 43-52.

90. Güntekin, B., Saatçi, E., Yener, G., 2008. Decrease of evoked delta, theta and alpha coherence in Alzheimer patients during a visual oddball paradigm. Brain Res. 1235, 109116.

91. Haas, L.F., 2003. Hans Berger (1873-1941), Richard Caton (1842-1926), and electroencephalography. J Neurol Neurosurg Psychiatry. 74(1), 9.

92. Hall, J.R., Bernat, E.M., Patrick, C.J., 2007. Externalizing psychopathology and the errorrelated negativity. Psychol. Sci. 18, $326-333$.

93. Harmony, T., 2013. The functional significance of delta oscillations in cognitive processing. Front. Integ. Neurosci. 5, 83.

94. Harper, J., Malone, S.M., Bernat, E.M., 2014. Theta and delta band activity explain N2 and P3 ERP component activity in a go/no-go task. Clin. Neurophysiol. 125(1), 124-32.

95. Haupt, M., González-Hernández, J.A., Scherbaum, W.A., 2008. Regions with different evoked frequency band responses during early-stage visual processing distinguish mild Alzheimer dementia from mild cognitive impairment and normal aging. Neurosci. Lett. 19, 442(3), 273-8.

96. Hebb, D.O., 1949. The organization of behavior: A neuropsychological theory. Wiley, New York. 
97. Heider, F., 1977. Cited in Dewey, R.A. 2007. Psychology: An introduction: Chapter four The Whole is Other than the Sum of the Parts.

98. Henry, M.J., Obleser, J., 2012. Frequency modulation entrains slow neural oscillations and optimizes human listening behavior. Proc. Natl. Acad. Sci. USA. 109(49), 2009-2010.

99. Herrmann, C.S., Munk, M.H., Engel, A.K., 2004. Cognitive functions of gamma-band activity: memory match and utilization. Trends in Cog. Sci. 8(8), 347-355.

100. Herrmann, C.S., Strüber, D., Helrich, R.F., Engel, A.K. (2016). EEG Oscillation: From correlation to causality. International Journal of Psychophysiology, 103, 121.

101. Hillyard, S.A., Galambos R., 1967. Effects of stimulus and response contingencies on a surface negative slow potential shift in man. EEG Clin. Neurophysiol. 22(4), 297-304.

102. Hillyard, S.A., Hink, R.F., Schwent, V.L., Picton, T.W., 1973. Electrical signs of selective attention in the human brain. Science, 182, 177-180.

103.Ishii, R., Canuet, L., Herdman, A., Gunji, A., Iwase, M., Takahashi, H., Nakahachi, T., Hirata M., Robinson, S.E., Pantev, C., Takeda, M., 2009. Cortical oscillatory power changes during auditory oddball task revealed by spatially filtered magnetoencephalography. Clin. Neurophysiol. 120 (3), 497-504.

104.Jahnsen, H.L., Llinás, R., 1984. Electrophysiological properties of guinea-pig thalamic neurons: an in vitro study. J. Physiol. 349, 205-226.

105.James, W., 1890. The Principles of Psychology, 2 vols. Dover Publications.

106.Jensen, O., Colgin, L.L., 2007. Cross-frequency coupling between neuronal associations. Trends in Cog. Neurosci. 11, 267-269.

107.Jensen, O., Kaiser, J., Lachaux, J.P., 2007. Human gamma oscillations associated with attetion and memory. Trends Cog. Neurosci. 30, 317-324.

108.Jones, K.A., Porjesz, B., Chorlian, D., Rangaswamy, M., Kamarajan, C., Padmanabhapillai, A., Stimus, A., Beqleiter, H., 2006. S-transformtime-frequency analysis of P300 reveals deficits in individuals diagnosed with alcoholism. Clin. Neurophysiol. 117 (10), 21282143.

109. Karakaş, S., Başar, E., 1998. Early gamma response is sensory in origin: a conclusion based on cross-comparison of results from multiple experimental paradigms. Int. J. Psychophysiol. 31, 13-31.

110. Karakaş, S., Başar, E., 2006a. Models and theories of brain function within a framework of behavioral cognitive psychology. Int. J. Psychophysiol. (Special Issue on "Models and Theories of Brain Function with Special Emphasis on Cognitive Processing, 60(2), 186193.

111. Karakaş, S., Başar, E., (Guest Eds.), 2006b. Models and theories of brain function with special emphasis on cognitive processing. Int. J. Psychophysiol. 60(2), 97-201.

112.Karakaş, S., Başar-Eroğlu, C., Özesmi, Ç., Kafadar, H., Erzengin, Ö.U., 2001. Gamma response of the brain: A multifunctional oscillation that represents a bottom-up with top-down processing. Int. J. Psychophysiol. 39(2-3), 137-150.

113.Karakaş, S., Bekçi, B., Erzengin, Ö.U., 2003. Early gamma response in human neuroelectric activity is correlated with neuropsychological test scores. Neurosci. Lett. $340,37-40$. 
114. Karakaş, S., Erzengin, Ö.U., Başar, E., 2000. A new strategy involving multiple cognitive paradigms demonstrates that ERP components are determined by the superposition of oscillatory responses. Clin. Neurophysiol. 111, 1719-1732.

115. Keil, A., Müller, M. M., Gruber, T., Wienbruch, C., Stolarova, M., Elbert, T., 2001. Effects of emotional arousal in the cerebral hemispheres: A study of oscillatory brain activity and event-related potentials. Clin. Neurophysiol. 112, 2057-2068.

116. Klimesch, W., Doppelmayr, M., Röhm, D., Pöllhuber, D., Stadler, W., 2000. Simultaneous desynchronization and synchronization of different alpha responses in the human electroencephalograph: a neglected paradox? Neurosci. Lett. 284, 97-100.

117. Klimesch, W., Schimke, H., Schwaiger, J., 1994. Episodic and semantic memory: an analysis in the EEG theta and alpha band. EEG Clin. Neurophysiol. 91, 428-441.

118. Knyazev, G.G., 2012. EEG delta oscillations as a correlate of basic homeostatic and motivational processes. Neurosci. Biobehav. Rev. 36(1), 677-95.

119. Knyazev, G.G., Savostyanov, A.N., Levin, E.A., 2006. Alpha synchronization and anxiety: implications for inhibition vs. alertness hypotheses. Int. J. Psychophysiol. 59, 151-158.

120.Knyazev, G.G., Slobodskoj-Plusnin, J.Y., Bocharov, A.V., 2009. Event-related delta and theta synchronization during explicit and implicit emotion processing. Neurosci. 164, 1588-1600.

121. Koffka, K., 1935. Principles of Gestalt Psychology. Harcourt, Brace \& World, New York.

122.Kolev, V., Demiralp, T., Yordanova, J., Ademoğlu, A., Isoglu-Alkaç, U., 1997. Timefrequency analysis reveals multiple functional components during oddball P300. Neuroreport. 27,8(8), 2061-2065.

123. Kösem, A., Gramfort, A., vanWassenhove, V., 2014. Encoding of event timing in the phase of neural oscillations. Neurolmage, 92, 274-284.

124.Luck, J.L., 2014. An Introduction to Event-Related Potential Technique (2nd ed). MIT Pr., Cambridge.

125. Makeig, S., Debener, S., Onton, J., Delorme, A., 2016. Mining event-related brain dynamics. Trends Cog. Neurosci. 8(5), 204-210.

126. Makeig, S., Westerfield, M., Jung, T.P., Enghoff, S., Townsend, J., Courchesne, E., Seinowski, T.J., 2002. Dynamic brain sources of visual evoked responses. Science, 295, 690-694.

127. Martini, N., Menicucci, D., Sebastiani, L., Bedini, R., Pingitore, A., Vanello, N., Milanesi, M., Landini, L., Gemignani, A., 2012. The dynamics of EEG gamma responses to unpleasant visual stimuli: From local activity to functional connectivity. Neurolmage, 60, 922-932.

128. Mathewson, K.E., Gratton, G., Fabiani, M., Beck, D.M., Ro, T., 2009. To see or not to see: prestimulus alpha phase predicts visual awareness. J. Neurosci. 29(9), 2725-2732.

129. McClelland, J.L., Rumelhart, D.E., PDP Research Group (Eds.), 1986. Parallel Distributed Processing. Explorations in the Microstructure of Cognition (Vol. 2). Psychological and Biological Models. MIT Books, Cambridge.

130. Mesulam, M.M., 1990. Large-scale neurocognitive networks and distributed processing for attention, language, and memory. Ann. Neurol. 28(5), 597-613.

131. Miller, G.A., 1956. The magical number seven, plus or minus two: Some limits on our capacity for processing information. Psychol. Rev. 63(2), 81-97. 
132. Min, B.K., Busch, N.A., Debener, S., Kranczioch, C., Hanslmayr, S., Engel, A.K., Herrmann, C.S., 2007. The best of both worlds: phase-reset of human EEG alpha activity and additive power contribute to ERP generation. Int. J. Psychophysiol. 65(1), 58-68.

133. Miskovic, V., Schmidt, L.A., 2009. Frontal brain oscillatory coupling among men who vary in salivary testosterone levels. Neurosci. Lett. 464, 239-242.

134. Mountcastle, V.B., 1992. Preface, in: Başar, E., Bullock, T.H. (Eds.), Induced Rhythms in the Brain. Birkhäuser, Boston, pp. 217-231.

135. Mountcastle, V.B., 1998. Perceptual Neuroscience: The Cerebral Cortex. Harvard Univ. Press, Cambridge.

136. Mousavi, S.M., Adamoğlu, A., Demiralp, T., Shayesteh, M.G., 2014. A wavelet transform based method to determine depth of anesthesia to prevent awareness during general anesthesia. Comp. Math Methods Medi. 354739.

137.Müller, M.M., Keil, A., Gruber, T., Elbert, T., 1999. Processing of affective pictures modulates right-hemispheric gamma band EEG activity. Clin. Neurophysiol. 110, 19131920.

138. Näätänen, R., Gaillard, A.W., Mäntysalo, S., 1978. Early selective-attention effect on evoked potential reinterpreted. Acta Psychologica (Amst). 42(4), 313-329.

139. Neisser, U., 1967. Cognitive Psychology. Appleton-Century-Crofts, New York.

140.Öniz, A., Başar, E., 2009. Prolongation of alpha oscillations in auditory oddball paradigm. Int. J. Psychophysiol. 71(3), 235-41.

141.Özdemir, A.K., Karakaş, S., Çakmak, E.D., Tüfekçi, D.i.., Arıkan, O., 2005. Time-frequency component analyser and its application to brain oscillatory activity. J. Neurosci. Methods. 145, 107-125.

142.Özerdem, A., Güntekin, B., Atagün, I., Turp, B., Başar, E., 2011. Reduced long distance gamma $(28-48 \mathrm{~Hz})$ coherence in euthymic patients with bipolar disorder. J. Aff. Dis. 132, 325-332.

143.Pearson, J., 1790. A Plain and Rational Account of the Nature and Effects of Animal Magnetism: in a Series of Letters. With Notes and an Appendix. By the editor. Eighteenth Century Collections Online, London.

144.Picton, T.W., Hillyard, S.A., 1974. Human auditory evoked potentials. II. Effects of attention. EEG Clin. Neurophysiol. 36(2), 191-9.

145. Pinal, D., Zurrón, M., Díaz, F., 2014. Effects of load and maintenance duration on the time course of information encoding and retrieval in working memory: from perceptual analysis to post-categorization processes. Front. Hum. Neurosci. 8, 165.

146. Pineda, J.A., 2005. The functional significance of mu rhythms: translating "seeing" and "hearing" into "doing". Brain Res. Rev. 50 (1), 57-68.

147.Polich, J., 2007. Updating P300: an integrative theory of P3a and P3b. Clin. Neurophysiol. 118(10), 2128-48.

148.Prada, L., Barceló, F., Herrmann, C.S., Escera, C., 2014. EEG delta oscillations index inhibitory control of contextual novelty to both irrelevant distracters and relevant tasks witchcues. Psychophysiol. 51 (7), 658-672.

149.Pravdich-Neminsky, V.V., 1913. Ein versuch der registrierung der elektrischen gehirnerscheinungen. Zbl Physiol. 27, 951-960. 
150.Rahn, E., Başar, E., 1993a. Prestimulus EEG-activity strongly influences the auditory evoked vertex response: a new method for selective averaging. Int. J. Neurosci. 69(1-4), 207-20.

151. Rahn, E., Başar, E., 1993b. Enhancement of visual evoked potentials by stimulation during low prestimulus EEG stages. Int. J. Neurosci. 72, 123-136.

152. Rémond, A., Lesèvre, N., 1967. Variations in average visual evoked potentials as a function of the alpha rhythm phase autostimulation. EGG Clin. Neurophysiol. Supp. 26, 42-52.

153.Rodriguez, E., George, N., Lachaux, J., Martinerie, J., Renault, B., Varela, F., 1999. Perception's shadow: long-distance synchronization of human brain activity. Nature, 397, 430-433.

154.Rubinov, M., Sporns, O., 2010. Complex network measures of brain connectivity: Uses and interpretations. Neuroimage, 52(3), 1059-1069.

155.Sakihara, K., Gunji, A., Furushima,W., Inagaki, M., 2012. Event-related oscillations in structural and semantic encoding of faces. Clin. Neurophysiol. 123, 270-277.

156. Schroeder, C.E., lakatos, P., 2009. Low-frequency neuronal associations as instruments of sensory selection. Trends Neurosci. 32(1), 9-18.

157. Schultz, D., 2000. A History of Moddern Psychology ( $3^{\text {rd }}$ ed.). Academic Pr., New York.

158.Schürmann, M., Başar, E., 1994. Topography of alpha and theta oscillatory responses upon auditory and visual stimuli in humans. Bio. Cybern. 72, 161-174.

159.Schutter, D.J.L.G., van Honk, J., 2005. Salivary cortisol levels and the coupling of midfrontal delta-beta oscillations. Int. J. Psychophysiol. 55, 127-129.

160.Silva, L.R., Amitai, Y., Connors, B.W., 1991. Intrinsic oscillations of neocortex generated by layer 5 pyramidal neurons. Science, 251, 432-435.

161.Singer, W., Gray, C.M., 1995. Visual feature integration and the temporal correlation hypothesis. Ann. Rev. Neurosci. 18, 555-586.

162. Stampfer, H.G., Başar, E., 1985. Does frequency analysis lead to better understanding of human event-related potentials? Int. J. Neurosci. 26, 181-196.

163.Stefanics, G., Hangya, B., Hernádi, I., Winkler, I., Lakatos, P., Ulbert, I., 2010. Phase entrainment of human delta oscillations can mediate the effects of expectation on reaction speed. J. Neurosci. 30 (41), 13578-13585.

164.Sternberg, R., 2006. Cognitive Psychology (4th ed.) Thomson/Wadsworth, Belmont.

165.Sutton, S., Braren, M., Zubin, J., John, E.R., 1965. Evoked-potential correlates of stimulus uncertainty. Science. 150(3700), 1187-8.

166. Ungerleider, L.G., Haxby, J.V., 1994. "What" and "where" in the human brain. Curr. Opinions Neurobiol. 4, 15-165.

167. Ungerleider, L.G., Mishkin, M., 1982. Two cortical visual systemes, in: Ingle, D.J., Goodale, M.A., Mansfield, R.J.W. (eds.), Analysis of Visual Behavior. MIT Press, Cambridge.

168.Van Deursen, J.A., Vuurman, E.F., van Kranen-Mastenbroek, V.H., Verhey, F.R., Riedel, W.J., 2011. 40-Hz steady state response in Alzheimer's disease and mild cognitive impairment. Neurobiol. Aging. 32(1), 24-30. 
169.Vecchio, F., Babiloni, C., Lizio, R., De Vico, F.F., Blinowska, K., Verrienti, G., Frisoni, G., Rossini, P.M., 2013. Resting state cortical EEG rhythms in Alzheimer's desiease: towards EEG markers for clinical applications. A review. Supp. Clin. Neurophysiol. 62, 223.

170.Walter, W.G., 1953. The Living Brain. Duckworh, London.

171.Wen, H., Liu, Z., 2016. Seperating fractal and oscillatory components in the power spectrum of neurophysiologcal signal. Brain Topography, 29(1), 13-26.

172. Wundt, W., 1874. Grundzüge der Physiologischen Psychologie. Wilhelm Engelmann, Leipzig.

173. Wundt, W., 1896. Outline of Psychology. Engellman, Leipzig.

174. Yener, G., Başar, E., 2010. Sensory evoked and event related oscillations in Alzheimer's discase, a short review. Cog. Neurodyn. 4, 263-274.

175. Yener, G., Başar, E., 2013. Biomarkers in Alzheimer's disease with a special emphasis on event-related oscillatory responses. Supp. Clin. Neurophysiol. 62, 237-73.

176.Yener, G., Güntekin, B., Başar, E., 2008. Event-related delta oscillatory responses of Alzheimer patients. Eur. J. Neurol. 15, 540-547.

177. Yener, G.G., Güntekin, B., Orken D.N., Tülay E., Forta, H., Başar, E., 2012. Auditory event related delta responses are decreased in Alzheimer's disease. Behav. Neurol. 25, 3-11.

178.Yener, G., Güntekin, B., Öniz, A., Başar, E., 2007. Increased frontal phase-licking of event related theta oscillations in Alzheimer patients treated with acetylcholine esterase inhibitors. Int. J. Psychophysiol. 64, 46-52.

179.Yener, G., Güntekin, B., Tülay, E., Başar, E., 2009. A comparative analysis of sensory visual evoked oscillations with visual cognitive event related oscillations in Alzheimer's disease. Neurosci. Lett. 462, 193-197.

180.Zweig, S., 1932. Mental Healers: Franz Anton Mesmer, Mary Baker Eddy, Sigmund Freud (translated by E. and C.Paul). Viking Pr., New York.

\section{FIGURE CAPTIONS}

Figure 1. Decomposition of the averaged ERP (continuous line) to the target stimulus in an oddball paradigm (recording site: $\mathrm{Fz}$ ), delta response (dashed-continuous line) and theta response (dotted line). Stimulation applied at " 0 " time point.

Figure 2. Developmental changes in the (A) power spectra, (B) visual evoked potentials, (C) digitally filtered alpha response (filter range: 8-13 Hz). Recording site: 01 . Stimulation applied at "0" time point.

Figure 3. Superimposed single sweep (thin lines) and grand averaged (dark lines) theta responses obtained upon visual stimuli (recording site: F3). Decreased phase-locking is observed in the $A D$ group (B) in comparison to the healthy control group (A).

TABLE LEGENDS 
Table 1. An Overview of the Extinct (1-3) and Currently Influential (4-6) Schools of Psychology.

Table 2. A Brief Description of the Brain's Electrical Responses. 


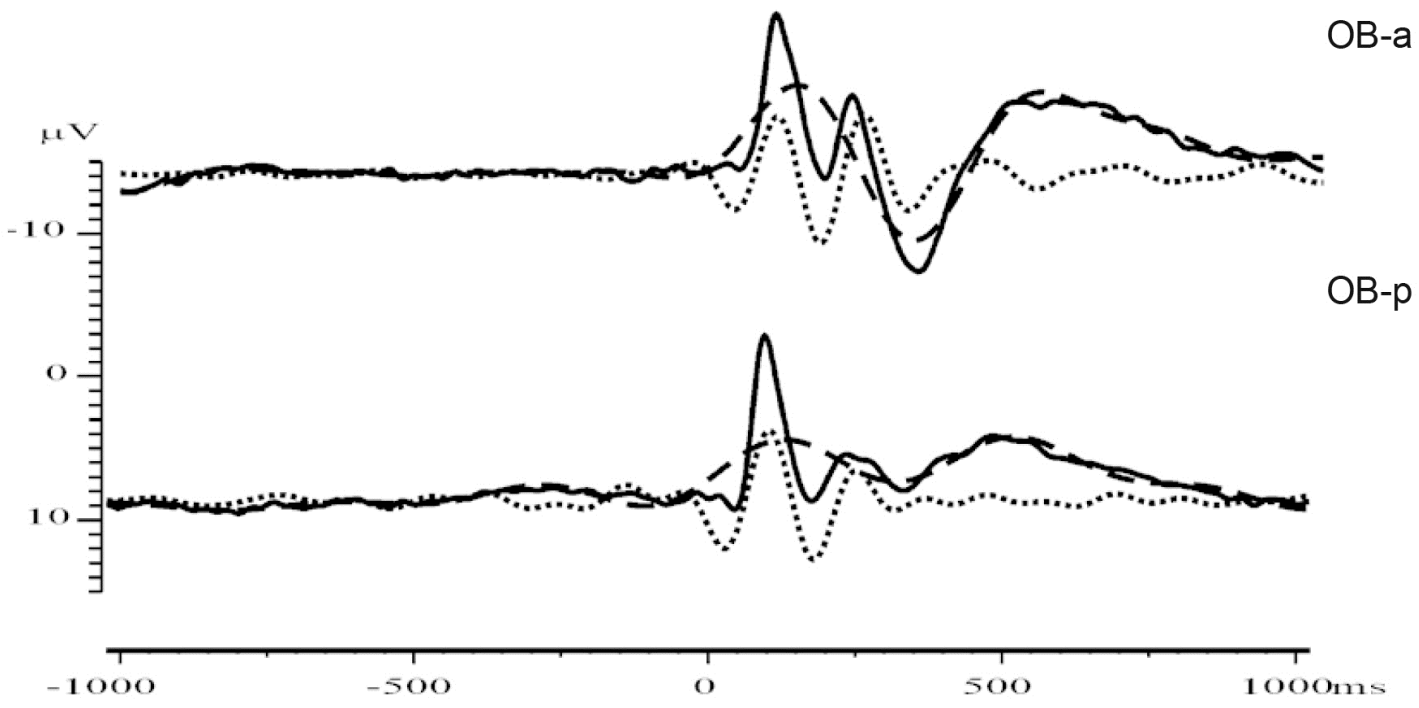

Figure 1. Decomposition of the averaged ERP (continuous line) to the target stimulus in an oddball paradigm (recording site: $\mathrm{Fz}$ ), delta response (dashed-continuous line) and theta response (dotted line). Stimulation applied at " 0 " time point. 
A
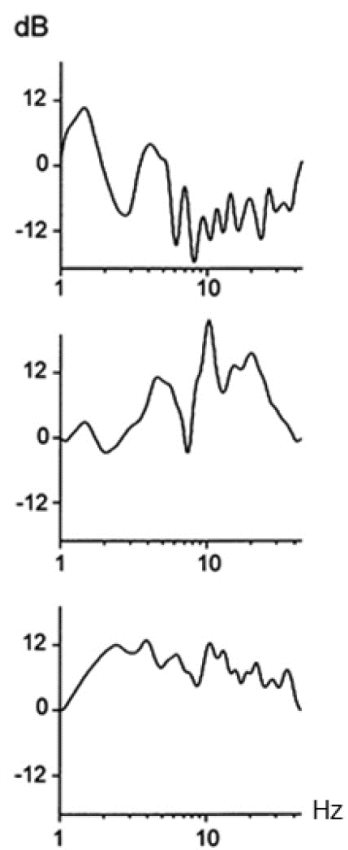

B
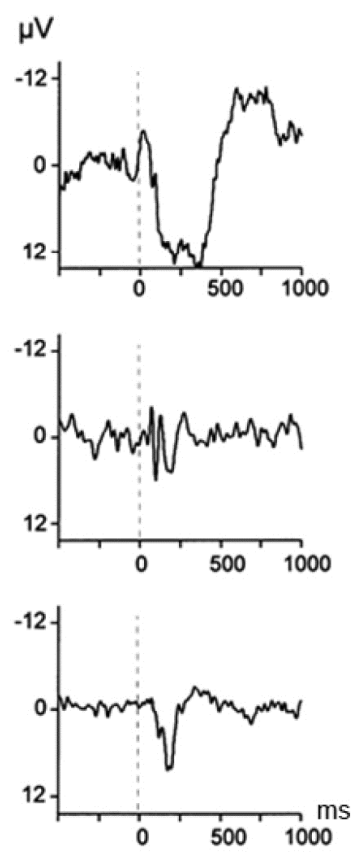

C
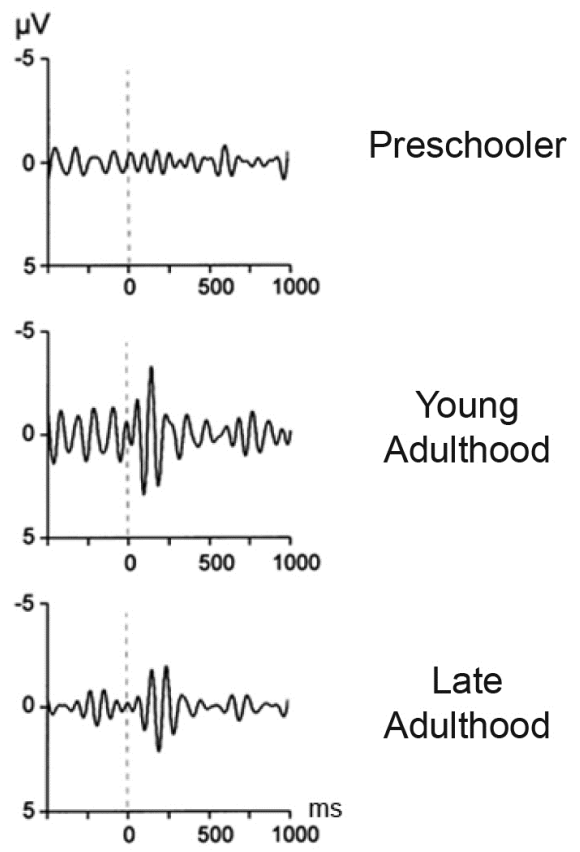

Figure

Figure 2. Developmental changes in the power spectra (A), visual evoked potentials (B), and digitally filtered alpha response (filter range: 8-13 Hz). Recording site: 01 . Stimulation applied at " 0 " time point. 
Table 1. An Overview of the Extinct (1-3) and Currently Influential (4-6) Schools of Psychology.

\begin{tabular}{|c|c|c|c|c|c|c|c|}
\hline & School Founded by... & Predecessors & $\begin{array}{c}\text { Influential } \\
\text { period }\end{array}$ & Location & Followers & Methods & $\begin{array}{c}\text { Keyword/ } \\
\text { Definition of psychology }\end{array}$ \\
\hline 1. & Structuralism by Wilhem Wundt & $\begin{array}{l}\text { British Empiricists } \\
\text { and Associationists } \\
\text { Natural Philosophy }\end{array}$ & $\begin{array}{l}1879- \\
\cong 1900\end{array}$ & Germany & $\begin{array}{l}\text { E.B. Titchener } \\
\text { H Ebbinghaus } \\
\text { G.E. Müller } \\
\text { O. Külpe }\end{array}$ & Introspection & $\begin{array}{l}\text { Consciousness/ The analysis of conscious } \\
\text { experiences of normal humans into its } \\
\text { components }\end{array}$ \\
\hline 2. & $\begin{array}{l}\text { Functionalism by } \\
\text { John Dewey }\end{array}$ & $\begin{array}{l}\text { C. Darwin } \\
\text { F. Galton } \\
\text { H. Spencer }\end{array}$ & $\begin{array}{l}1896- \\
\cong 1930\end{array}$ & USA & $\begin{array}{l}\text { J.R. Angell } \\
\text { H.A. Carr } \\
\text { R.S. Woodworth }\end{array}$ & $\begin{array}{l}\text { Introspection } \\
\text { Natural observation } \\
\text { Experimentation }\end{array}$ & $\begin{array}{l}\text { Consciousness/The study of goal- } \\
\text { oriented, adaptive responses of humans } \\
\text { and animals. }\end{array}$ \\
\hline 3. & $\begin{array}{l}\text { Radical Behaviorism by } \\
\text { J. B. Watson }\end{array}$ & $\begin{array}{l}\text { G. Romanes } \\
\text { C.L. Morgan } \\
\text { J. Loeb } \\
\text { I.P. Pavlov } \\
\text { V.M. Bekhterev } \\
\text { E.L. Thorndike } \\
\text { R. Yerkes }\end{array}$ & $\begin{array}{l}1913- \\
\cong 1950\end{array}$ & USA & $\begin{array}{l}\text { E.B. Holt } \\
\text { A.P. Weiss } \\
\text { K. Lashley } \\
\text { P. Bridgeman } \\
\text { B.F. Skinner }\end{array}$ & $\begin{array}{l}\text { Objective methods } \\
\text { Experimentation }\end{array}$ & $\begin{array}{l}\text { Behavior/The study of objectively } \\
\text { observable responses to external stimuli }\end{array}$ \\
\hline 4. & $\begin{array}{l}\text { Psychoanalysis by } \\
\text { Sigmund Freud }\end{array}$ & $\begin{array}{l}\text { Platon } \\
\text { G.L. Leibnitz } \\
\text { J.F. Herbart } \\
\text { F.A. Mesmer } \\
\text { J.M. Charcot } \\
\text { P. Janet } \\
\text { J. Breuer }\end{array}$ & 1895- & Germany & $\begin{array}{l}\text { C.G. Jung } \\
\text { A. Adler } \\
\text { K. Horney } \\
\text { E. Fromm } \\
\text { A. Freud } \\
\text { A. Erikson }\end{array}$ & $\begin{array}{l}\text { Hypnosis } \\
\text { Dreams } \\
\text { Free association }\end{array}$ & $\begin{array}{l}\text { Unconscious/ The study of unconscious } \\
\text { motivating forces, the conflicts between } \\
\text { these forces and the effect of these } \\
\text { conflicts on behavior }\end{array}$ \\
\hline 5. & $\begin{array}{l}\text { Gestalt by } \\
\text { Max Wertheimer }\end{array}$ & $\begin{array}{l}\text { I. Kant } \\
\text { F. Brentano } \\
\text { E. Mach } \\
\text { D. Katz } \\
\text { E. Rubin } \\
\text { C. von Ehrenfels }\end{array}$ & 1913- & Germany & $\begin{array}{l}\text { K. Koffka } \\
\text { W. Köhler } \\
\text { K. Lewin }\end{array}$ & $\begin{array}{l}\text { Subjective/phenomenal } \\
\text { observation }\end{array}$ & $\begin{array}{l}\text { Cognition/ The study of phenomenal } \\
\text { cognitive processes } \\
\text { "The whole is other than the sum of its } \\
\text { parts" }\end{array}$ \\
\hline 6. & $\begin{array}{l}\text { Liberal Behaviorism by } \\
\text { George A. Miller }\end{array}$ & $\begin{array}{l}\text { Behaviorism and } \\
\text { behaviorists }\end{array}$ & 1956- & USA & $\begin{array}{l}\text { E. C. Tolman } \\
\text { E.R. Guhrie } \\
\text { C.L. Hull }\end{array}$ & $\begin{array}{l}\text { Experimentation } \\
\text { Advanced statistical } \\
\text { techniques } \\
\text { Intricate research designs }\end{array}$ & $\begin{array}{l}\text { Behavior and cognition/ The study of } \\
\text { both the objectively observable } \\
\text { responses to external stimuli and the } \\
\text { phenomena that intervene between the } \\
\text { stimulus and response }\end{array}$ \\
\hline
\end{tabular}




\section{HIGHLIGHTS}

- The paper reviews the historical evolution that led to the study of the brain (body)mind relationship on the basis of brain oscillations.

- It outlines and illustrates the principles of neuro-oscillatory dynamics via selected research findings.

- The possibility of using the oscillatory activity as biomarkers for neuropsychiatric disorders is discussed.

- Contribution of the academics in psychology departments to the growing research on oscillatory activity is evaluated. 